http://dx.doi.org/10.35381/racji.v5i8.568

\title{
Proyecto de reforma a la Ley de Fomento Ambiental: Optimización de los Ingresos del Estado
}

\section{Reform project to the Environmental Development Law: Optimization of State Revenue}

\author{
Guillermo Emilio Abad-Romero \\ guillermo.abad@psg.ucacue.edu.ec \\ Universidad Católica de Cuenca, Cuenca \\ Ecuador \\ https://orcid.org/0000-0003-2840-1503 \\ Juan Carlos Erazo-Álvarez \\ jcerazo@ucacue.edu.ec \\ Universidad Católica de Cuenca, Cuenca \\ Ecuador \\ https://orcid.org/0000-0001-6480-2270 \\ Diego Adrián Ormaza-Ávila \\ daormazaa@ucacue.edu.ec \\ Universidad Católica de Cuenca, Cuenca \\ Ecuador \\ https://orcid.org/0000-0002-3492-0943 \\ Cecilia Ivonne Narváez-Zurita \\ inarvaez@ucacue.edu.ec \\ Universidad Católica de Cuenca, Cuenca \\ Ecuador \\ https://orcid.org/0000-0002-7437-9880
}

Recibido: 11 de noviembre de 2019

Aprobado: 14 de diciembre de 2019

\section{RESUMEN}

Este artículo de revisión contiene un análisis de las trasgresiones a los principios constitucionales de legalidad y competencia, debido al accionar de la Asamblea Nacional del Ecuador al momento de presentar y admitir a trámite el Proyecto de Ley Reformatoria a la Ley de Fomento Ambiental y Optimización de los Ingresos del Estado, cuyo fin era la derogatoria del impuesto ambiental a la contaminación vehicular. Se ha 
utilizado como metodología el análisis cualitativo en base en los métodos histórico, analítico sintético y deductivo. Por medio del estudio realizado se llega a la conclusión de que, a la presente fecha, subsiste aun en Ecuador la práctica de arrogarse funciones por parte de algunas instituciones y exceder las competencias instituidas por la Constitución y la ley, en una flagrante inobservancia de los principios constitucionales que rigen el accionar público.

Descriptores: Constitución; Impuesto a la contaminación vehicular; Principio de legalidad; Principio de competencia; Procedimiento legislativo; Seguridad jurídica.

\section{ABSTRACT}

This review article contains an analysis of the transgressions to the constitutional principles of legality and competence, due to the actions of the National Assembly of Ecuador at the time of submitting and admitting for processing the Draft Law Reform to the Law of Environmental Development and Optimization of State Income, whose purpose was the repeal of the environmental tax on vehicle pollution. Qualitative analysis has been used as a methodology based on historical, synthetic and deductive analytical methods. Through the study carried out, it is concluded that, as of this date, there is still the practice in Ecuador of taking over functions by some institutions and exceeding the powers established by the Constitution and the law, in a flagrant nonobservance of the constitutional principles that govern public action.

Descriptors: Constitution; Vehicle pollution tax; Principle of legality; Competition principle; Legislative procedure; Legal security.

\section{INTRODUCCIÓN}

Con la aprobación mediante referéndum de la Constitución de Montecristi y su consecuente entrada en vigencia a finales del año 2008, el Ecuador sufrió una serie de cambios e innovaciones que se sintetizan en lo que varios tratadistas han denominado neo constitucionalismo; esto, ha traído como consecuencia la introducción de grandes transformaciones políticas y estructurales, cuyo propósito es la reinstitucionalización del Estado y la eliminación de los conflictos sociales y la inequidad (Ávila, 2011).

El pleno respeto a la Constitución de la República, asegura el debido funcionamiento del Estado y una armónica interrelación de las personas que habitan en él y las 
instituciones públicas. Los distintos organismos que conforman el Estado, deben encaminar su actividad a la búsqueda del bien común, ciñendo sus actuaciones a las disposiciones plasmadas en la Constitución de la República y la Ley, observando lo plasmado en el artículo 226 de la Carta Magna que en esencia señala que las Instituciones del Estado deberán ejercer únicamente las competencias que la Constitución y la Ley les confiere, coordinando las acciones para conseguir sus fines y hacer efectivo el goce y ejercicio de los derechos (Asamblea Constituyente, 2008). Consecuentemente, el marco de actuación de los organismo públicos, está constreñido a lo que la propia Constitución y las leyes correspondientes establecen, lo cual guarda plena relación con lo establecido en el artículo 82 de la Constitución que determina el derecho a la seguridad jurídica, estando las instituciones del Estado obligadas a actuar sujetándose a normas previas, claras, públicas y en apego al ámbito de sus competencias (Corte Constitucional del Ecuador, 2015).

Pese a que la Constitución de la República contiene una serie de mandatos y disposiciones de carácter imperativo, en el Ecuador no existe un estricto cumplimiento de las normas establecidas en ella; obviándose el contenido de las disposiciones constitucionales en algunos casos, y en otros, realizándose una interpretación errónea y discrecional del texto normativo con el fin de acomodarlo a intereses y necesidades particulares, sin tomar en consideración que la misma Constitución de la República del Ecuador en su artículo 427 establece taxativamente la forma en que deben ser interpretadas las disposiciones de carácter constitucional.

Entre los actos que son realizados por parte de la Administración Pública se encuentran los denominados actos normativos, a través de los cuales se crean normas de carácter general que mandan, prohíben o permiten y que son expedidos por las distintas instituciones del Estado en base a las potestades conferidas por la Carta Suprema. La Constitución ha establecido varios organismos con potestad normativa, entre los cuales destaca la Asamblea Nacional como órgano legislativo encargado de emitir las leyes, 
las cuales deben guardar coherencia y armonía con el texto Constitucional, (Guzmán Chávez, 2019).

En el proceso de creación normativa, la Asamblea Nacional debe indefectiblemente circunscribirse al trámite establecido en la Constitución de la República del Ecuador, en un marco de respeto a las competencias que le corresponden a cada uno de los poderes legítimamente constituidos, las cuales han sido conferidas de manera explícita por la misma Constitución de la República y que constituyen el fundamento de todo Estado democráticamente instituido; de otro modo, se daría una intromisión de un poder en la esfera de actuación de otro, lo que trae como consecuencia la transgresión de los principios fundamentales y deviene en que los actos realizados bajo esas condiciones carezcan de legitimidad (Granda Torres \& Herrera Abrahan, 2019).

Aunque la norma fundamental establece las pautas para la creación, modificación y extinción de tributos; las disposiciones constitucionales no fueron observadas a cabalidad al momento de presentarse el Proyecto de Ley Reformatoria a la Ley de Fomento Ambiental y Optimización de los Ingresos del Estado, provocando la transgresión de los principios constitucionales de legalidad y competencia (Astudillo Mamarandi \& Lucio Solano, 2019).

Esto nos conlleva a plantear como problema de la presente investigación: Determinar que la Asamblea Nacional se arrogó atribuciones y competencias que no le correspondían en la iniciativa de presentación de proyectos de ley en materia tributaria, lo que trajo como consecuencia el quebrantamiento del orden constitucional; y, consecuentemente circunscribir el objetivo de este trabajo a demostrar la transgresión a los principios de legalidad y competencia como resultado de la actuación discrecional de la Asamblea Nacional al momento de presentar la iniciativa legislativa para derogar el comúnmente llamado impuesto verde. 


\section{DESARROLLO}

\section{Promulgación del Decreto-Ley de Fomento Ambiental y Optimización de los Ingresos del Estado y posterior propuesta de reforma}

Para poder comprender a cabalidad el tema en estudio es necesario remontarse al año 2011; en el cual, se planteó por parte del Ejecutivo de aquel entonces el proyecto de Ley de Fomento Ambiental y Optimización de los Ingresos del Estado, en cuya exposición de motivos se señalaba entre otras cosas, que la emisión de dicho proyecto no solo tenía como fin la creación de tributos para la recaudación de fondos sino también fomentar la adopción de conductas sociales y ambientales responsables; así como también, lograr que los ciudadanos disminuyan el consumo de sustancias dañinas para el organismo como el alcohol y tabaco (Presidencia de la República del Ecuador, 2011).

Este proyecto de ley, presentado por el entonces Presidente Constitucional del Ecuador Eco. Rafael Correa Delgado, fue remitido a la Asamblea Nacional en fecha 24 de octubre de 2011 para ser tramitado en dicho órgano legislativo de conformidad con lo que manda la Constitución de la República; sin embargo, la Asamblea no dio a este proyecto el trámite de rigor y por consiguiente el mismo no fue aprobado, modificado o archivado dentro del plazo de 30 días que prevé la Carta Magna. Ante la inacción del órgano legislativo, la Presidencia de la República en uso de las atribuciones conferidas por el artículo 140 de la Constitución y artículo 62 de la Ley Orgánica de la Función Legislativa, promulgó el referido proyecto de Ley de Fomento Ambiental y Optimización de los Ingresos del Estado como Decreto - Ley.

El decreto-ley es un tipo de acto normativo con particularidades propias, que produce efectos similares a los de la ley; es decir, se constituye en una regla de carácter obligatorio dirigido a un conjunto de personas (Hervada, 2011). Su principal diferencia con la ley radica en que el decreto-ley es emitido por el poder ejecutivo, mientras que la ley es expedida por el poder legislativo. 
Para que un Decreto-Ley pueda ser promulgado, deben cumplirse ciertas condiciones determinadas en la misma Constitución de la República y la ley; entre ellas, la emisión de este acto normativo debe tener su fundamento en razones de estricta necesidad. En el Ecuador, esta estricta necesidad se encuentra presente en aquellos proyectos de ley catalogados como urgentes en materia económica; se debe indicar, sin embargo, que el uso de esta figura jurídica se ha vuelto común hoy en día, utilizándose de manera habitual para crear normas con rango de ley, lo que ha traído como consecuencia un mayor protagonismo del poder ejecutivo en la creación normativa en detrimento del órgano legislativo (Arana, 2013).

Dada la configuración política de nuestro país, la Asamblea Nacional asume un rol preponderante en la expedición de normas, es pues el legislador natural por excelencia debido a su condición de representante directo de la democracia; no obstante, en el caso de la figura del Decreto-Ley, se extiende esta facultad al poder ejecutivo con la finalidad de atender necesidades normativas urgentes (Carmona, 2013). La emisión de un decreto-ley es la clara muestra de que, en determinadas situaciones, la facultad de legislar rebasa la competencia exclusiva del órgano legislativo.

Con el Decreto-Ley de Fomento Ambiental y Optimización de los Ingresos del Estado emitido por el ex presidente Correa, se dio paso a la creación de un nuevo impuesto sin precedentes en el Ecuador, a través del cual se imponía a los automotores a partir de los 1500 centímetros cúbicos de cilindraje al pago de un tributo por la contaminación que ocasionaban, cuyo valor se calculaba en función del cilindraje del motor y los años de antigüedad de los vehículos, estableciéndose como salvedad que en ningún caso el valor del impuesto podía superar el $40 \%$ del valor del avalúo del vehículo.

Esta forma de calcular el valor a cancelar en función del cilindraje del vehículo y su antigüedad, evidentemente no era lo más técnico; debido a que, no siempre los vehículos de mayor potencia, cilindraje o antigüedad son aquellos que más contaminan, sino que esto responde a varios factores de ingeniera automotriz ligados al precio, marca y tecnología de cada vehículo, de manera tal que, existen ciertos casos de 
vehículos con motores relativamente grandes que contaminan menos que otros de menor cilindraje.

El impuesto a la contaminación vehicular estuvo vigente desde el año 2011 y empezó a regir desde el año 2012; en un inicio, el valor a pagar por este tributo era relativamente bajo, por cuanto durante los tres primeros años los vehículos con un cilindraje mayor a los 2500 centímetros cúbicos y más de 5 años de antigüedad tenían una reducción del $80 \%$, en razón de que el Estado se encontraba "subsidiando" parcialmente este valor; luego, a partir del año 2014 esa reducción era únicamente del 50\%; y finalmente, a partir del año 2019 el sujeto pasivo debía cancelar el 100\% del valor de dicho impuesto, aumentando así considerablemente los montos que debían ser pagados de manera anual por los destinatarios del impuesto.

Tras 8 años de vigencia del comúnmente denominado "impuesto verde", el 24 de enero del 2019, los asambleístas del partido CREO, Fabricio Villamar y Homero Castanier, mediante oficio $\mathrm{N}^{\circ} \mathrm{FV}-\mathrm{AN}-0015-2019$ presentaron ante la Presidenta de la Asamblea Nacional, la iniciativa de Ley Reformatoria a la Ley de Fomento Ambiental y Optimización de los ingresos del Estado, el cual tenía como propósito eliminar el impuesto a la contaminación vehicular. Esta propuesta, se fundamentaba en el hecho de que a través de este impuesto se obligaba al pago de altas sumas de dinero a aquellos propietarios de vehículos con cilindrajes altos y varios años de antigüedad, sin tomar en consideración que en gran parte de los casos, las personas que poseían automotores con estas características pertenecían a las clases sociales menos pudientes y por ende no tenían la capacidad económica que les permita adquirir un vehículo más moderno y que produzca menos contaminación y que además se excluía del pago de este impuesto a los vehículos del servicio público que son los que más contaminan (Villamar y Castanier, 2019). Posteriormente el Consejo de Administración Legislativa mediante resolución NCLA-2017-2019-683 calificó el proyecto presentado por los Asambleístas y remitió el mismo a la comisión correspondiente para su tratamiento (Consejo de Administración Legislativa, 2019). 


\section{Competencias de las instituciones del Estado desde la óptica de los principios y derechos constitucionales}

La emisión de actos normativos nace de la potestad que la Constitución y la Ley otorga a los diferentes órganos estatales, teniendo cada uno de estos órganos funciones específicas que tienen su fundamento en la división de poderes; de manera tal que cada uno de estos poderes ejerce un rol único y fundamental para el correcto funcionamiento del Estado. Esto tiene su origen en la evolución que han tenido la mayoría de países, en donde se ha pasado de gobiernos monárquicos a gobiernos constituidos democráticamente.

En un Estado de carácter democrático, la toma de decisiones está en manos de representantes elegidos por la mayoría de los ciudadanos, sin importar su posición económica, social o cultural en una clara muestra de la igualdad que poseemos todos como seres humanos, dotados de los mismos derechos y obligaciones y con capacidad de elegir o ser elegidos; consiguiéndose a través de la democracia, la construcción de elecciones colectivas en donde el poder se ejerce por representantes dotados de la capacidad de tomar decisiones (Ferrajoli, 2003).

Dentro de esta perspectiva es la democracia un logro de las sociedades modernas que han superado su configuración de Estados políticamente administrados por gobiernos plenipotenciarios, que regían de manera antojadiza y arbitraria sin considerar las necesidades de la generalidad de personas. Con esta evolución, la democracia se constituiría en "premisa y principio fundante del Estado constitucional contemporáneo" (Mora, 1997, p. 280).

La democracia es un tipo de sistema político que permite elegir representantes de la misma colectividad y que comparten las mismas necesidades de las grandes mayorías, con el objetivo de que las medidas adoptadas por estos, estén adecuadas a la realidad de cada pueblo, de tal forma que, para que exista una verdadera representación democrática se necesita que en la toma de decisiones estén presentes representantes de todos los sectores, en función del territorio, costumbres, estratos sociales, etc. Solo 
con la presencia de representantes que reflejen la diversidad de miembros de una sociedad se puede lograr una verdadera democracia que permita que el accionar de los órganos del Estado responda a las necesidades de la población en general (Serrano de Barrios, 2019).

Con la evolución de los sistemas políticos de los países y la institucionalización del principio democrático como eje fundamental de la organización de los Estados, se alcanzó lo que se conoce como Estado Constitucional de Derecho cuyo objetivo principal es el reconocimiento y amparo de los derechos propios de las personas (Reyes, 1993). Para lograr este objetivo, se perfeccionaron las Constituciones, las cuales pasaron de ser simples cuerpos normativos que regulaban el ejercicio del poder a ser auténticas declaraciones de derechos, dotadas de rigidez como una consecuencia natural de su superioridad para evitar su fácil reforma a través del proceso legislativo ordinario; consecuentemente, su modificación o derogación es posible únicamente a través de los procedimientos que las mismas constituciones establecen (Alaez, 1996).

El principal fin de las constituciones es el respeto irrestricto de la libertad y demás derechos inherentes al ser humano, con su creación se dejó atrás la concentración plenipotenciaria del poder que estaba en manos del monarca, pasando a ser la constitución la norma suprema por excelencia y de este modo sometiendo a los actos de los poderes del Estado a límites plenamente establecidos en ella (Del RosarioRodríguez, 2011).

En efecto en un Estado Constitucional, las constituciones tienen un carácter bilateral, en razón de que obligan jurídicamente tanto a la administración como a los administrados; esta capacidad de obligar la constituye en una norma jurídica (Palomino, 2007). Cabe señalar también que, estas normas de carácter supremo regulan en cada Estado su organización, los órganos o poderes que los conforman, las facultades que posee cada uno de estos poderes, etc.; y, además, establecen los procedimientos y competencias para que se lleve a cabo un proceso sumamente importante: la producción normativa. 
En un sistema jurídico como el ecuatoriano, confluyen una infinidad de órganos con potestad normativa y con ello la existencia simultánea de una infinidad de normas jurídicas, las cuales necesariamente deben guardar armonía y coherencia con la norma fundamental. Todas las disposiciones que conforman el sistema normativo se encuentran subordinadas a la Constitución, pues es precisamente de ella de dónde emanan los principios que otorgan validez y legitimidad al resto de normas. Son supremas porque dotan de competencia a los órganos del Estado y establecen el proceso a seguirse para la emisión de normas ordinarias (Kelsen, 2005).

De lo anotado se desprende que, las constituciones a más de organizar el funcionamiento del Estado y establecer principios y derechos, contienen también preceptos que deben cumplirse al momento de crearse las demás normas del ordenamiento jurídico, instituyendo parámetros que deben ser observados para que dichas normas gocen de validez. La Constitución por su carácter de norma suprema prevalece sobre cualquier otra norma del ordenamiento jurídico y además establece las condiciones que deben cumplirse para que las normas infra constitucionales gocen de eficacia. Por lo tanto, toda ley o disposición jurídica creada en contraposición a la Carta Magna, debería considerarse inválida; al respecto Palomino (2007) señala:

Se dice que la Constitución es también fuente material, en la medida en que no obstante habilitar la creación del Derecho en todas las direcciones, representa a su vez, el parámetro de validez del resto de normas del ordenamiento. De modo tal, ninguna otra expresión normativa podrá sustraerse del contexto marcado por la norma fundamental $y$, por el contrario, sólo será válida una norma o cualquier otra expresión del Derecho, en la medida en que no se salga de los cauces marcados por la Constitución (p.231).

La supremacía constitucional es la piedra angular de todo Estado democráticamente constituido, los actos realizados por los órganos del poder se encuentran sujetos a la Constitución y las normas infra constitucionales son válidas en la medida en que su contenido se ajusta al texto constitucional y son promulgadas en apego al 
procedimiento que la misma constitución como norma suprema y fundamental establece para el efecto.

Lo acotado en líneas anteriores guarda estricta relación con los principios de legalidad y reserva de ley, los que en algunas ocasiones erróneamente se interpretan como términos semejantes o equivalentes, pero en realidad se tratan de dos instituciones jurídicas con particularidades propias y que se encuentran íntimamente relacionadas entre sí. El principio de legalidad establece la obligatoriedad de la administración de sujetarse a la norma; mientras que la reserva de ley, es una figura jurídica que determina competencias privativas de la ley en determinadas materias, lo que la vuelve distinta a las demás normas inferiores. (Casás, 2002).

En lo esencial el principio de legalidad contemplado en la Constitución de la República del Ecuador, obliga a las autoridades a ejercer únicamente las facultades que la Constitución y la Ley les otorgan y actuar en los términos exactos que han sido previamente establecidos en el ordenamiento jurídico, evitando de esta forma una actuación discrecional de los organismos del Estado que podría devenir en un abuso de autoridad. Esto desde luego, aplica también en el proceso de creación normativa. Hoy en día, muchos tratadistas sostienen que este principio de legalidad ha evolucionado a un verdadero principio de "juridicidad", en razón de que, el ordenamiento jurídico ha experimentado avances significativos que han dado cabida a la existencia de principios y derechos que se encuentran concebidos fuera de la letra de la ley.

Por su parte, el principio de Reserva de ley, evita la regulación de ciertos aspectos jurídicos mediante la creación de cuerpos normativos distintos a la ley. No es más que una limitación al poder que ejercen ciertos órganos que gozan de la capacidad de crear normas para que estos no estén facultados para promulgar a su arbitrio disposiciones jurídicas que regulen aspectos que deben ser regulados únicamente a través del procedimiento legislativo, lo cual guarda íntima relación con el principio democrático, dada la concepción de la legislatura como representante directo del pueblo. Los órganos del Estado no tienen la facultad de exigir el pago de prestaciones 
patrimoniales, si previamente no ha sido emitida una norma jurídica por parte de los representantes democráticamente elegidos (Romero-Flor, 2013).

Lo acotado, tiene su fundamento en el hecho de que mediante este tipo de normas se regulan aspectos que tienen incidencia en la totalidad o al menos en la gran mayoría de las personas; por lo que, en aras de precautelar el principio democrático, es menester que dichas normas sean creadas y promulgadas por un órgano dotado de legitimidad democrática; en nuestro caso la Asamblea Nacional. En materia tributaria, el principio de Reserva de Ley no es absoluto en cuanto a tributos se refiere, por cuanto en nuestro país existen otros órganos facultados para crearlos, como lo son los Gobiernos Autónomos Descentralizados en lo que respecta a las tasas y contribuciones especiales que son cobradas en cada una de las circunscripciones territoriales.

Lo que sí podría afirmarse en todo caso, es que en el Ecuador existe reserva de ley en lo que respecta a la creación de impuestos, en cuanto esto le concierne exclusivamente al órgano legislativo. La creación o modificación de impuestos puede ser realizada únicamente mediante la expedición de un cuerpo normativo emitido por parte de la Legislatura; no obstante, para ello debe observarse el procedimiento legislativo establecido en la Constitución de la República y en la Ley Orgánica de la Función Legislativa dado que al igual que todos los actos realizados por parte de los organismos que conforman el Estado, la creación de normas se encuentra condicionada al respeto irrestricto a estos dos principios fundamentales; "Los principios de legalidad y de reserva de ley condicionan la producción normativa (...)" (Zaidán, 2017, p. 71).

Cabe señalar que los principios de legalidad y reserva de ley se encuentran íntimamente ligados al principio constitucional de competencia, el cual, desde un sentido general, podría entenderse como la capacidad que tiene un determinado órgano para realizar una determinada acción o cumplir una determinada función, en virtud de una potestad conferida por la Constitución y las leyes de la República. Este principio se encuentra directamente ligado al proceso de creación de normas jurídicas pues determina el órgano que puede ejercer la competencia normativa y la materia sobre la 
cual se puede estatuir, lo que trae como consecuencia la validez o invalidez de una determinada norma en función del cumplimiento de los requisitos establecidos (Palomino, 2007).

Como ya se señaló anteriormente, el Ecuador cuenta con varios órganos dotados de competencia normativa, entre los cuales destaca la Asamblea Nacional. Para que una ley pueda ser promulgada, se debe respetar el procedimiento legislativo establecido en la Constitución, Ley Orgánica de la Función Legislativa y demás normativa aplicable, respetando el número de debates, el número de votos necesarios para su aprobación y además sometiéndola al veto presidencial establecido en el ordenamiento jurídico vigente.

Si bien, la facultad de crear leyes le corresponde de forma exclusiva a la Asamblea Nacional, la iniciativa de presentar los proyectos de ley puede o debe provenir de otros órganos en función de su naturaleza; como ocurre con la facultad exclusiva que ha sido conferida al poder ejecutivo en materia económica, aunque por mandato constitucional, sea la misma Asamblea la que deba conocer y tratar los proyectos remitidos por la Presidencia de la República. (Troya y Simone, 2014).

\section{Vulneración de los principios constitucionales con la transgresión de competencias exclusivas del Poder Ejecutivo en materia tributaria}

La Constitución de la República del ecuador, ha conferido potestades exclusivas en materia económica y tributaria al presidente de la república dada la configuración de nuestro sistema jurídico, en el cual, al igual que en la gran mayoría de países democráticos existe al menos en teoría una división de poderes del Estado. La Constitución de la República del Ecuador prevé en su artículo 135 que únicamente el Presidente tiene la facultad de presentar proyectos que creen, modifiquen o eliminen impuestos, aumenten el gasto público o modifiquen la división político administrativa del país; privando a la Asamblea Nacional, a otras Instituciones y a la iniciativa popular de esta competencia (Asamblea Constituyente, 2008). 
El artículo 301 de la Constitución de la República del Ecuador señala asimismo que únicamente por iniciativa presidencial y a través de una ley promulgada por la Asamblea se pueden establecer, modificar o extinguir impuestos (Asamblea Constituyente, 2008). En este orden de ideas, mientras no exista la iniciativa por parte del Presidente de la República de crear, modificar o extinguir un determinado impuesto, no puede realizarse dicho acto por ninguna otra vía, ni siquiera a través de una consulta popular, puesto que la Constitución ha previsto esta facultad como exclusiva del poder ejecutivo. La creación de tributos cumple con el principio democrático en la medida en que estos son establecidos o modificados a través de una ley emitida por parte del órgano legislativo, pero con el requisito sine qua non de que la iniciativa de su creación, modificación o extinción es competencia exclusiva del Presidente de le República (Racines, 2016).

Consecuentemente, la iniciativa planteada por un órgano distinto al ejecutivo de crear modificar o derogar un determinado impuesto, deviene en un acto ilegítimo, que no podría ser tratado por la Asamblea Nacional, pues desde el momento mismo de su iniciativa, dicho acto debería ser considerado nulo, por ser opuesto al contexto constitucional. Como se indicó en líneas anteriores, el principio constitucional de competencia determina las facultades que le corresponden a cada uno de los organismos o poderes que conforman un Estado, lo cual se aplica igualmente en materia tributaria para la creación o modificación de tributos.

En el caso del impuesto a la Contaminación Vehicular, al cual se ciñe nuestro estudio, debe indicarse que tras varios años de estar vigente el impuesto a la Contaminación Vehicular y ante el malestar de la ciudadanía por los altos montos que debían cancelarse por este concepto, asambleístas del partido CREO decidieron presentar la iniciativa de reforma a la ley que contenía el impuesto a la contaminación vehicular, con lo cual se buscaba eliminar el pago de este tributo. Para la presentación de esta iniciativa los asambleístas que propusieron el proyecto de reforma, sustentaron su iniciativa en lo establecido en la parte final del inciso último del artículo 140 de la 
Constitución de la República que establece que la Asamblea Nacional podrá modificar o derogar los decretos-ley en cualquier tiempo (Asamblea Constituyente, 2008).

No obstante, es necesario señalar que en este punto se realizó una errónea interpretación del texto constitucional; pues si bien es cierto, se le confiere a la Asamblea la potestad de modificar o derogar los decretos-ley en cualquier tiempo, la misma norma constitucional establece que esta modificación o derogación deberá ser realizada sujetándose al trámite ordinario previsto en la constitución; es decir, se deben observar las disposiciones constitucionales relacionadas con la iniciativa de presentar proyectos de ley, respetando el principio de competencia que ha sido señalado en el presente estudio.

Al establecer el artículo 135 de la Constitución de manera taxativa que solo el Presidente o Presidenta puede presentar proyectos de ley que creen, modifiquen o extingan derechos, mal podría presentarse un proyecto de tal naturaleza por un órgano distinto, como sucedió en este caso, en donde fueron los asambleístas los que presentaron dicha iniciativa, haciendo una errónea interpretación del texto plasmado al final del artículo 140 de la Constitución de la República. En consecuencia, la iniciativa presentada por los Asambleístas, para la derogatoria del Impuesto a la Contaminación Vehicular, adolecía de nulidad, por cuanto esta facultad es exclusiva del poder ejecutivo y la inobservancia de esta facultad privativa plasmada en la constitución, representa una intromisión en las competencias propias de cada uno de los poderes del Estado.

No se pretende a través de este artículo cuestionar la voluntad de los legisladores de derogar un impuesto que a todas luces era negativo para la ciudadanía en general, ni poner en tela de duda la buena fe con la que se actuó al presentar la iniciativa de derogatoria de dicho tributo con el objetivo de evitar que se sigan esquilmando de manera desproporcionada los recursos de los ciudadanos ecuatorianos; sino más bien, a través de este análisis se pretende poner en evidencia la errónea interpretación que se realizó del texto constitucional, lo cual ocasionó la transgresión de los principios constitucionales de legalidad y competencia al invadir la esfera de actuación de un 
órgano al cual la Constitución le ha dotado de una facultad exclusiva. A continuación se presenta la figura 1 que pretende ilustrar el procedimiento legal que se debió seguir.

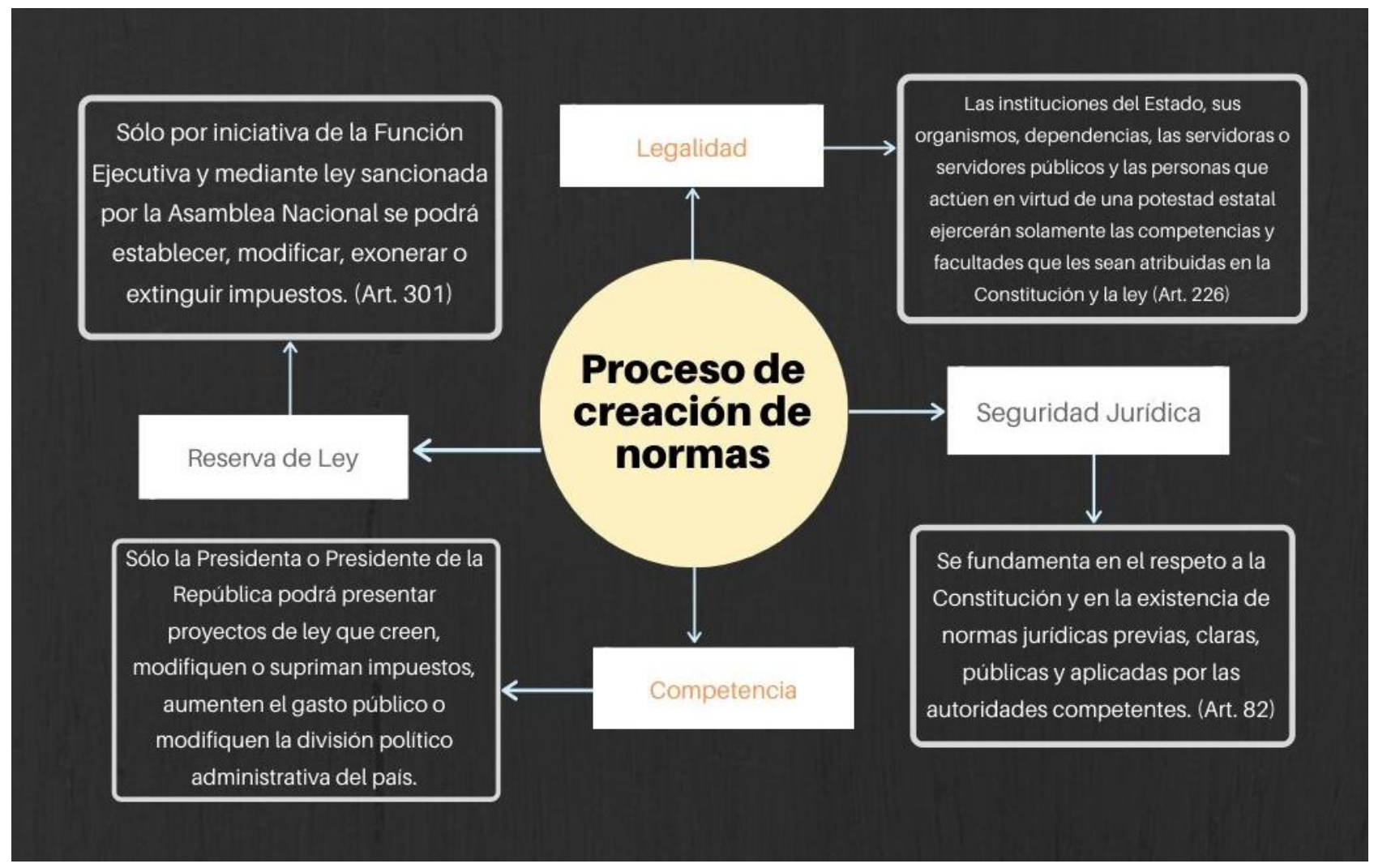

Figura 1. Representación de los principios constitucionales que deben ser observados por la Asamblea Nacional y demás órganos dotados de competencia normativa en la creación de normas jurídicas, para que estas gocen de validez y legitimidad.

\section{METODOLOGÍA}

En la presente investigación ha sido utilizado como herramienta metodológica el enfoque cualitativo mediante la utilización de varias fuentes bibliográficas de varios tipos a través de las cuales se ha conseguido información veraz y suficiente que permita entender de manera apropiada el problema jurídico que se aborda en el trabajo realizado. Se ha utilizado el método deductivo; es decir mediante el análisis de premisas se ha llegado a una conclusión específica (Dávila, 2006). Histórico - Lógico; mediante este método se llega a la conclusión de que los eventos o fenómenos que se 
suscitan en la sociedad no se presentan de forma aislada, sino que responden a un proceso que da lugar a su origen (CENTTY, 2006). Analítico - sintético; que comprende dos procesos, el análisis mediante el cual a través de un ejercicio mental se logra descomponer un elemento y analizar sus cualidades y la síntesis que funciona de manera inversa, es decir a partir de un ejercicio mental se logra unir las partes de un todo y sacar conclusiones (Rodríguez y Pérez, 2017). Mediante la aplicación de los métodos antes aludidos, se pudo analizar el material bibliográfico, comprendido en libros, artículos de revista, disposiciones constitucionales, leyes y jurisprudencia; generándose a través del estudio de instrumentos jurídicos aportes al derecho, en la construcción de un marco de respeto a los mandatos y principios constitucionales (Mosquera, Erazo y Narváez, 2019).

\section{APORTES}

Sobre lo analizado en el presente estudio, se realizan las siguientes reflexiones:

La creación del impuesto a la contaminación vehicular o impuesto verde como comúnmente era llamado, obedecía a la voluntad de un gobierno que, en su afán de obtener recursos para solventar el desproporcionado gasto público, impuso entre otros, este tributo que no se congraciaba con la realidad económica del Ecuador.

Para lograr este objetivo, se calificó al proyecto de ley que creaba el impuesto ambiental a la contaminación vehicular como urgente en materia económica, con el fin de evitar el engorroso trámite legislativo ordinario. Su promulgación se facilitó aún más ante desavenencia de los miembros de la Asamblea Nacional de ese entonces, expidiéndose como Decreto-Ley el proyecto planteado.

El proyecto de los Asambleístas para derogar el impuesto a la contaminación vehicular, desde el punto de vista de justicia y equidad se encontraba debidamente sustentado, en virtud de que a todas luces el denominado impuesto verde no cumplió con su objetivo de reducir la contaminación; por el contrario, lo único que se consiguió a través de él, fue imponer una carga tributaria excesiva a ciudadanos cuya condición económica no 
les permitía adquirir vehículos más nuevos. Sin embargo, aunque la intención era justa, la forma en la que se pretendía derogar este impuesto resultaba inconstitucional por cuanto la norma fundamental establecía de manera clara y puntual las competencias y atribuciones de cada uno de los poderes en lo que respecta a la creación, modificación y extinción de impuestos.

Poco tiempo después de que el Consejo de Administración Legislativa calificó el proyecto de ley y remitió el mismo ante la Comisión correspondiente para su tratamiento, el actual Presidente de la República remitió a la Asamblea Nacional el proyecto de ley Derogatoria al impuesto Ambiental a la Contaminación Vehicular y este fue unificado por la Comisión de Desarrollo Económico con el proyecto presentado por los Asambleístas Villamar y Castanier. La presentación de esta iniciativa por parte del ejecutivo se realizó justamente cuando la Asamblea Nacional se encontraba ya tramitando el proyecto de ley planteado por iniciativa de los Asambleístas con el apoyo de al menos el cinco por ciento de los miembros de la Asamblea, situación que denota que el Presidente realizó esta acción en un intento de ganar popularidad, ya que, de cualquier forma, con o sin su iniciativa, se iba a derogar el impuesto verde.

De no haberse planteado en forma posterior por parte del ejecutivo otro proyecto de ley con el mismo propósito de derogar el impuesto verde, y si hubiese sido este derogado únicamente por iniciativa de los asambleístas, hubiera existido la posibilidad de plantear una demanda de inconstitucionalidad de dicho acto normativo ante la Corte Constitucional; órgano al cual le corresponde verificar que las disposiciones del ordenamiento jurídico guarden coherencia con la Constitución, ya sea en sentido formal o material (Corte Constitucional del Ecuador, 2013). Siendo lo correspondiente en este caso la acción de inconstitucionalidad por la forma, bajo el argumento de que el proceso de creación de la norma no se observó el procedimiento establecido en la Constitución de la República al haberse presentado la iniciativa de derogatoria del impuesto a la contaminación vehicular por parte de un órgano distinto al que establece la Constitución. 
Todas las Instituciones y poderes del Estado deben observar de manera irrestricta los principios, garantías y derechos establecidos en la Constitución de la República. Sólo a través del sometimiento de los organismos estatales al ordenamiento jurídico se podrá evitar los conflictos institucionales y las pugnas por el poder. Esta es la única vía para lograr una relación armónica entre las instituciones públicas y garantizar los derechos de las personas; pues, la Administración Pública está encaminada a coordinar acciones para conseguir los fines institucionales y hacer efectivo el goce y ejercicio de los derechos tal como prevé la norma suprema.

\section{REFERENCIAS CONSULTADAS}

1. Alaez Corral, B. (1996). Supremacía y rigidez constitucionales [A propósito del libro La rigidez de las Constituciones escritas, de Alessandro Pace y Joaquín Várela (1), y del debate celebrado el 20 de mayo de 1996 en la Universidad de Oviedo]. Revista Española de Derecho Constitucional, 373-394.

2. Arana García, E. (2013). Uso y abuso del decreto-ley. Revista de Administración Pública, 337-365.

3. Asamblea Constituyente. (2008). Constitución de la República del Ecuador. Organización territorial del Estado . Montecristi, Manabí, Ecuador.

4. Asamblea Constituyente. (2008). Constitución de la República del Ecuador. Régimen de desarrollo. Montecristi, Manabí, Ecuador.

5. Ávila Santamaria, R. (2011). El neoconstitucionalismo transformador el Estado y el derecho en la constitución de 2008. Quito: Abya-Yala.

6. Carmona Contreras, A. M. (2013). El decreto-ley en tiempos de crisis. Revista Catalana de dret públic, 1-20.

7. Casás, J. O. (2002). Derechos y garantías constitucionales del contribuyente : A partir del principio de reserva de ley tributaria. Buenos Aires: Ad Hoc.

8. Centty Villafuerte, D. B. (2006). Manual metodologico para el investigador cientifico. Arequipa, Perú: Facultad de economia de LA U.N.S.A. Obtenido de http://www.eumed.net/libros-

gratis/2010e/816/METODO\%20LOGICO\%20HISTORICO.htm 
9. Consejo de Administración Legislativa. (abril de 2019). Observatorio Legislativo. Obtenido de http://observatoriolegislativo.ec/media/archivos_leyes/Memorando_SAN-20195514._Notificacion_Resolucion_CAL.pdf

10. Corte Constitucional del Ecuador. (09 de Abril de 2013). SENTENCIA No. 00513-SIN-CC. Quito, Pichincha, Ecuador.

11. Corte Constitucional del Ecuador. (29 de abril de 2015). SENTENCIA N. ${ }^{\circ} 001-15-$ SDC-CC. Quito, Pichincha.

12. Dávila Newman, G. (2006). El razonamiento inductivo y deductivo dentro del proceso investigativo en ciencias experimentales y sociales. Laurus, 12, 180-205. Obtenido de https://www.redalyc.org/pdf/761/76109911.pdf

13. Del Rosario-Rodríguez, M. F. (junio de 2011). La supremacía constitucional: naturaleza y alcances. Díkaion, 20(1), 97-117.

14. Ferrajoli, L. (2003). Sobre la definición de "democracia". Una discusión con Michelangelo Bovero. Isonomía, 227-240.

15. Guzmán Chávez, M. (2019). El principio constitucional de la tutela judicial efectiva vulnerado por la acción de nulidad de sentencias. IUSTITIA SOCIALIS, 4(7), 135-145. doi:http://dx.doi.org/10.35381/racji.v4i7.366

16. Granda Torres, G., \& Herrera Abrahan, C. (2019). Análisis de los tipos penales y su importancia para determinar responsabilidad penal. IUSTITIA SOCIALIS, 4(7), 220-232. doi:http://dx.doi.org/10.35381/racji.v4i7.443

17. Hervada, J. (2011). ¿Qué es el derecho? La moderna respuesta del realismo jurídico una introducción al derecho. Navarra: Ediciones Universidad de Navarra, S.A.

18. Kelsen, H. (2005). Teoría general de Estado. México: Coyoacán.

19. Mora, G. (1997). La dimensión axiológica del principio constitucional democrático. Díkaion: revista de actualidad jurídica, 278-308.

20. Mosquera Choco, E. O., Erazo Álvarez, J. C., \& Narváez Zurita, C. I. (2019). Estrategias Administrativas y Financieras: herramientas clave para una gestión eficiente. Koinonía, 49. 
21.Palomino Manchego, J. F. (2007). Constitución, supremacía constitucional y teoría de las fuentes del Derecho: una visión desde el Perú. Cuadernos Constitucionales de la Cátedra Fadrique Furió Ceriol, 227-242.

22. Presidencia de la República del Ecuador. (24 de Noviembre de 2011). Ley de Fomento Ambiental y Optimización de los Ingresos del Estado. Exposición de motivos. Quito, Pichincha, Ecuador.

23. Racines, M. F. (2016). Los proyectos de ley tributarios «económicos urgentes» en Ecuador. Quito: Corporación Editora Nacional.

24. Reyes Riveros, J. (1993). Supremacía constitucional y sistema nacional de control. Revista Chilena de Derecho, 449-452.

25. Rodríguez Jiménez, A., \& Pérez Jacinto , A. O. (2017). Métodos científicos de indagación y de construcción del conocimiento. Revista Escuela de Administración de Negocios(82), 1-26. Obtenido de https://www.redalyc.org/pdt/206/20652069006.pdf

26. Romero-Flor, L. M. (2013). La reserva de ley como principio fundamental del derecho tributario. DIXI, 51-61.

27. Serrano de Barrios, N. (2019). La ley de infogobierno en el contexto tecnológico de la gestión pública. IUSTITIA SOCIALIS, 4(7), 201-219. doi:http://dx.doi.org/10.35381/racji.v4i7.395

28. Troya Jaramillo, J. V., \& Simone Lasso , C. A. (2014). Manual de derecho tributario. Quito: Corporación de Estidios y Publicaciones.

29. Villamar Jácome, P. F., \& Castanier Jaramillo, X. H. (2019). Observatorio legislativo. Obtenido de http://observatoriolegislativo.ec/media/archivos_leyes/FomentoAmbientallngreso Estado.pdf

(C2020 por los autores. Este artículo es de acceso abierto y distribuido según los términos y condiciones de la licencia Creative Commons Atribución-NoComercial-Compartirlgual 4.0 Internacional (CC BY-NC-SA 4.0) (https://creativecommons.org/licenses/by-nc-sa/4.0/). 